\title{
A combined statistical and dynamical approach for downscaling large-scale footprints of European windstorms
}

Article

Published Version

Haas, R. and Pinto, J. G. (2012) A combined statistical and dynamical approach for downscaling large-scale footprints of European windstorms. Geophysical Research Letters, 39 (23). L23804. ISSN 0094-8276 doi:

https://doi.org/10.1029/2012GL054014 Available at https://centaur.reading.ac.uk/32740/

It is advisable to refer to the publisher's version if you intend to cite from the work. See Guidance on citing.

Published version at: http://dx.doi.org/10.1029/2012GL054014

To link to this article DOI: http://dx.doi.org/10.1029/2012GL054014

Publisher: American Geophysical Union

All outputs in CentAUR are protected by Intellectual Property Rights law, including copyright law. Copyright and IPR is retained by the creators or other copyright holders. Terms and conditions for use of this material are defined in the End User Agreement.

www.reading.ac.uk/centaur 
Central Archive at the University of Reading

Reading's research outputs online 


\title{
A combined statistical and dynamical approach for downscaling large-scale footprints of European windstorms
}

\author{
R. Haas ${ }^{1}$ and J. G. Pinto ${ }^{1}$ \\ Received 26 September 2012; revised 31 October 2012; accepted 1 November 2012; published 5 December 2012.
}

[1] The occurrence of mid-latitude windstorms is related to strong socio-economic effects. For detailed and reliable regional impact studies, large datasets of high-resolution wind fields are required. In this study, a statistical downscaling approach in combination with dynamical downscaling is introduced to derive storm related gust speeds on a highresolution grid over Europe. Multiple linear regression models are trained using reanalysis data and wind gusts from regional climate model simulations for a sample of 100 top ranking windstorm events. The method is computationally inexpensive and reproduces individual windstorm footprints adequately. Compared to observations, the results for Germany are at least as good as pure dynamical downscaling. This new tool can be easily applied to large ensembles of general circulation model simulations and thus contribute to a better understanding of the regional impact of windstorms based on decadal and climate change projections. Citation: Haas, R., and J. G. Pinto (2012), A combined statistical and dynamical approach for downscaling large-scale footprints of European windstorms, Geophys. Res. Lett., 39, L23804, doi:10.1029/2012GL054014.

\section{Introduction}

[2] Windstorms are the main natural hazards affecting Europe, with a large impact on the societal and economic sectors [e.g., Fink et al., 2009]. Their occurrence over Western Europe may increase under future climate conditions [e.g., Della-Marta and Pinto, 2009]. Studies quantifying impacts on regional scales [e.g., Della-Marta et al., 2010; Schwierz et al., 2010] typically use a combination of large-scale data like reanalysis datasets or General Circulation Model (GCM) simulations, and Regional Climate Model (RCM) simulations. The high resolutions of RCMs (typically 10-50 km) involve high computational costs. Thus, they only focus on a region of interest and their applicability to multi-model ensembles is limited [cf. Kjellström et al., 2011].

[3] A computational inexpensive alternative is statistical downscaling, which relates large-scale predictors and local predictands by transfer functions. Different statistical downscaling techniques have been developed for various atmospheric parameters (e.g., Maraun et al. [2010] for a review). In recent years, some studies also concentrated on the

\footnotetext{
${ }^{1}$ Institute for Geophysics and Meteorology, University of Cologne, Cologne, Germany.

Corresponding author: R. Haas, Institute for Geophysics and Meteorology, University of Cologne, Kerpener Str. 13, DE-50937 Cologne, Germany. (rhaas@meteo.uni-koeln.de)

regionalization of wind data. For example, Bernardin et al. [2009] applied a system of stochastic differential equations on numerical weather prediction model data for wind refinement. A physical-statistical approach was introduced by $D e$ Rooy and Kok [2004], decomposing the total error between model and observation into small-scale representation mismatch and large-scale model error. Pryor et al. [2005] focused on wind energy applications and downscaled near-surface wind speed empirically using GCM data. Nevertheless, the research on statistical downscaling is still very limited for wind applications and none of the previous studies focused specifically on mid-latitude windstorms.

[4] The objective of this work is to develop and validate an approach suitable to reproduce dynamical downscaled RCM gust speeds in a cost-efficient way. This is important for building a storm catalog of many thousands of events, required for decadal projections, climate change investigations or insurance applications. We propose a new statistical downscaling tool, which is able to generate gust speeds on a high-resolution grid over Europe by Multiple Linear Regression (MLR) using RCM output for training purposes.

\section{Data}

\subsection{Reanalysis Data}

[5] In this study, ERA-Interim reanalysis data [Dee et al., 2011] from the European Centre for Medium-Range Weather Forecasts (ECMWF) is used as large-scale forcing for both dynamical and statistical downscaling. The dataset has a horizontal resolution of $\mathrm{T} 255\left(0.75^{\circ} \times 0.75^{\circ}\right)$ and covers the period from 1989 until the end of 2010. 6-hourly instantaneous wind speeds are used to establish a ranking of historical windstorms (details in Section 3.1.). For each storm, ERA-Interim data with original resolution within the investigation area $\left(-14.7656^{\circ} \mathrm{E}\right.$ to $34.4531^{\circ} \mathrm{E}, 32.6315^{\circ} \mathrm{N}$ to $66.3155^{\circ} \mathrm{N}$; Figure $\mathrm{S} 1$ in the auxiliary material) is compared to dynamically downscaled high-resolution data. ${ }^{1}$

\subsection{Regional Climate Model Data}

[6] The selected historical storms are dynamically downscaled with the COSMO-CLM (RCM of the COnsortium for Small-scale MOdelling in CLimate Mode, hereafter CCLM [Rockel et al., 2008]). A resolution of $7 \mathrm{~km}\left(0.0625^{\circ}\right)$ is reached by two step nesting using ERA-Interim as initial and boundary conditions. Wind gusts are estimated with an approach using friction velocity as a predictor for turbulence [Schulz, 2008]. For more details on RCM validation against

${ }^{1}$ Auxiliary materials are available in the HTML. doi:10.1029/ 2012GL054014 
observations and other gust estimation approaches, see Born et al. [2012]. Each simulation consists of at least 4 days.

\section{Methods}

\subsection{Selection of Events}

[7] Several methods have been developed to estimate the potential impact associated with windstorms based on wind or gust speeds [e.g., Klawa and Ulbrich, 2003]. Here, we consider a Meteorological Index (MI) to estimate potential losses, defined as spatially aggregated cubic exceedances of the local 98th gust percentile [see Pinto et al., 2012, equation 3]. This variable is a proxy for the impact of a storm purely associated with its meteorological characteristics, without considering exposure or vulnerability. MI is computed over Europe $\left(-9.8438^{\circ} \mathrm{E}\right.$ to $34.4531^{\circ} \mathrm{E} ; 35.4385^{\circ} \mathrm{N}$ to $64.912^{\circ} \mathrm{N}$; Figure S1), but only for land grid points. The 100 top-ranked days in the ERA-Interim period are derived according to MI (see Table S1). For training and validation of the statistical downscaling approach, events are defined as the storm date plus one day before and after. Several well known historical storms are included [cf. Fink et al., 2009]. Note that some consecutive days may be often attributed to the same storm (e.g., 20070118 and 20070119 for Kyrill). However, in order to maintain a consistent database on a daily basis, those dates are kept separated. A windstorm footprint (wind signature) for the full extension of a storm like Kyrill can be obtained by considering the maximum gust on both days at each grid point.

\subsection{Multiple Linear Regression}

[8] The statistical approach relates CCLM simulations and ERA-Interim data. We estimate a transfer function via MLR. One regression model is build per CCLM grid point:

$y_{i}=c_{0}+c_{1} x_{i 1}+\ldots+c_{k} x_{i k}+\epsilon_{i} \quad i=1, \ldots, e \quad k=1, \ldots, 16$

The model includes CCLM daily maximum gust speed (vmax) values as predictands $y_{i}$. The event set has been enlarged to a 300-day-list by adding one day before and after each event. Due to consecutive days in the 100-day-list (see Table S1), the 300-day-list includes duplication of calender days. These days have been excluded, thus $e=240$. The predictors $x_{i k}$ consist of the wind speeds at the 16 ERAInterim grid points next to the CCLM grid point. The vector of regression coefficients $\hat{c}=c_{k}$ can be estimated by the method of least squares:

$$
\hat{\mathbf{c}}=\left(\mathbf{X}^{T} \mathbf{X}\right)^{-1} \mathbf{X}^{T} \mathbf{y}
$$

with $\mathrm{X}=$ matrix of predictors and $\mathrm{y}=$ the vector of predictands. This transfer function is here reapplied on reanalysis data for cross-validation (see Section 3.3). However, the regression coefficients can be easily applied to other datasets (e.g., GCM).

\subsection{Validation}

[9] The effectiveness of the methodology is evaluated by cross-validation. Two distinct validation approaches are performed. First, the ability to reproduce the wind signature of a single storm with a transfer function estimated from the other 99 events (leave-one-out validation) is analysed.
Second, the list is separated into training and validation datasets according to dates and rank of MI. The separation can be performed with sequential (first and second 50 values) or disordered (even and odd entry numbers) lists. For both validation approaches, three-day-signatures are used.

[10] The root mean squared error (RMSE) and the relative root mean squared error $\left(R M S E_{\text {rel }}\right)$ are calculated per event and per grid point as a measure of skill:

$$
R M S E=\sqrt{\frac{\sum_{i=1}^{n}(\hat{x}-x)^{2}}{n}} \quad R M S E_{r e l}=\frac{\sqrt{\frac{\sum_{i=1}^{n}(\hat{x}-x)^{2}}{n}}}{\frac{\sum_{i=1}^{n} x}{n}}
$$

with $x=$ dynamically downscaled CCLM gusts and $\hat{x}=$ statistically downscaled gusts. For $R M S E$ and $R M S E_{\text {rel }}$ per event, $n=$ number of grid points. For $R M S E$ and $R M S E_{r e l}$ per grid point, $n=$ number of events $=100$.

\section{Results}

[11] The performance of the statistical downscaling is now compared with dynamical downscaling and forcing ERAInterim data (Figure 1). The leave-one-out validation of the statistically downscaled wind signatures shows that the method performs best for strong events with a broad wind signature associated with a typical cyclone propagating eastwards over the North and/or Baltic Sea (cf. example of storm Wiebke; Figure 1a). Larger deviations between dynamical and statistical downscaling are found for uncommon weather situations, e.g., days with multiple footprints (cf. Xynthia; Figure 1d) or footprints affecting areas where severe windstorms are unusual (e.g., Southwestern Europe, cf. Martin; Figure 1b). Due to the low number of such events, the MLR model has difficulties to reproduce them adequately. A mismatch also occurs if the CCLM footprints do not follow the ERA-Interim footprints tightly, as our method follows the large-scale input (cf. wind speeds West of Norway for Xynthia; Figure 1d).

[12] The absolute RMSE per event, i.e., the sum over all grid points, is 2 to $5 \mathrm{~ms}^{-1}$ (not shown). Summed over all events, the range is 1 to $6 \mathrm{~ms}^{-1}$ at most grid points (Figure 2a). The results are depicted except for the border of the model area, where the CCLM produces spurious values (compare, e.g., Figure $1 \mathrm{c}$ at the Northern and Eastern border). The statistical method performs best over most European onshore areas from Portugal to Belarus and results are biased by the number of events affecting each area. To take this into account, the number of events per grid point, where vmax exceeds $20 \mathrm{~ms}^{-1}$ (corresponding to $8 \mathrm{Bft}$, a common threshold used by insurance companies [cf. Klawa and Ulbrich, 2003]) is analyzed (Figure 2b). As a visible relation between the number of events and the absolute RMSE is revealed, a subset of grid points where less than one third of the events (33) reached this threshold is excluded, thus ensuring a reasonable sample size. Further, grid points above $2000 \mathrm{~m}$ are excluded to avoid deviations associated with underestimation of the model topography and unrealistic high dynamically downscaled gusts which are not in congruence with the large-scale forcing. As the absolute RMSE is larger in areas where the gust speeds are generally higher, Figure $2 \mathrm{c}$ displays $R M S E_{r e l}$ with excluded grid points shaded in grey. Over those areas the relative errors amount to $20-40 \%$, except over a small area over Southeastern France with up to $70 \%$. Better results are achieved over the colored area with a 5-30 \% range. 
(a) Wiebke 19900228 vmax CCLM
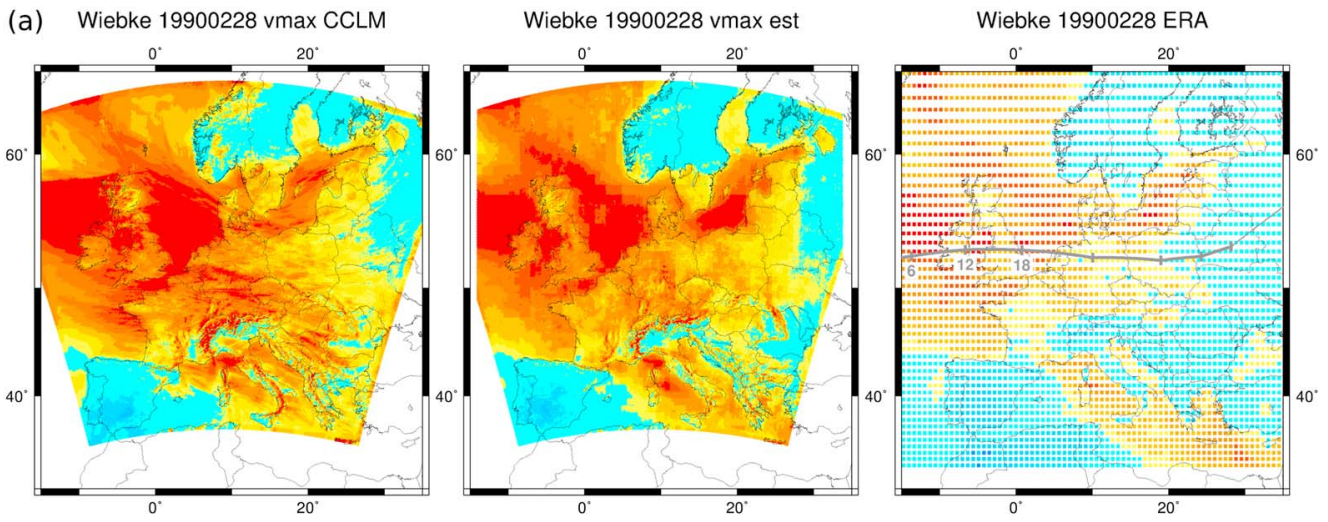

(b) Martin 19991228 vmax CCLM

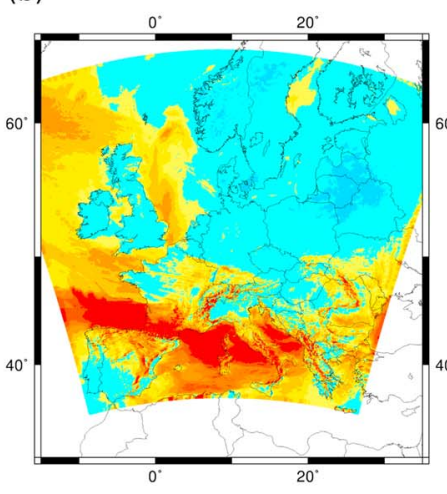

Martin 19991228 vmax est

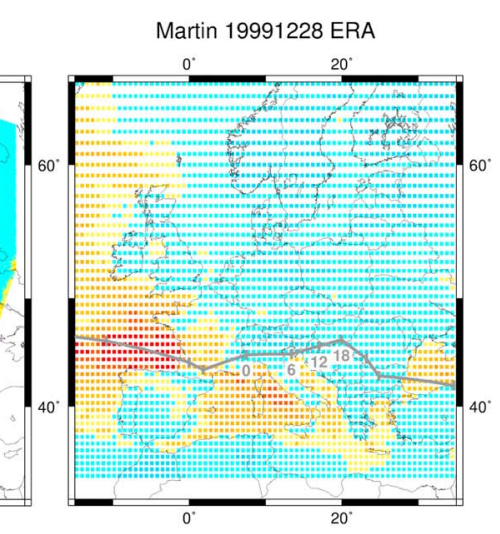

(c) Kyrill 20070118 vmax CCLM
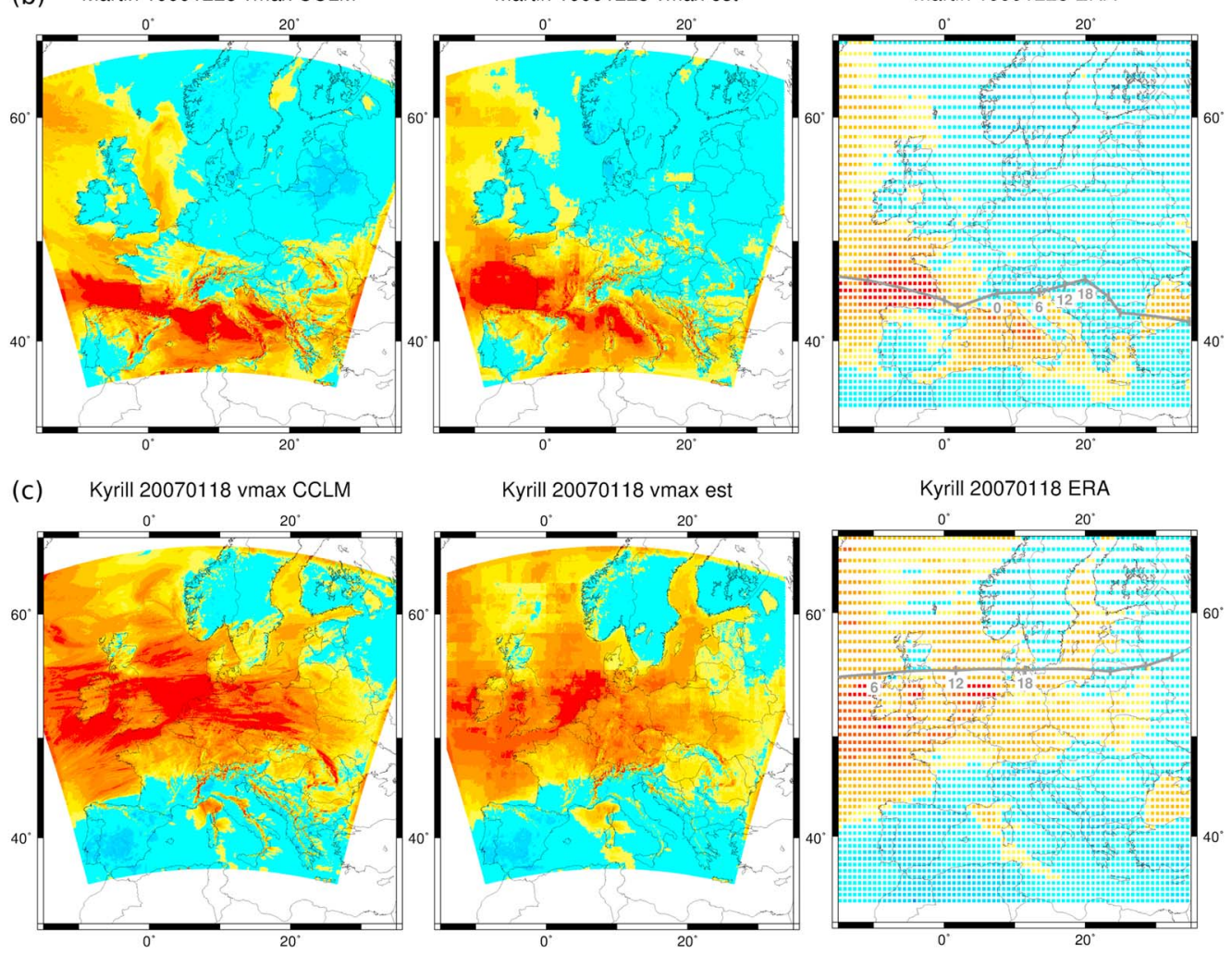

(d) Xynthia 20100228 vmax CCLM
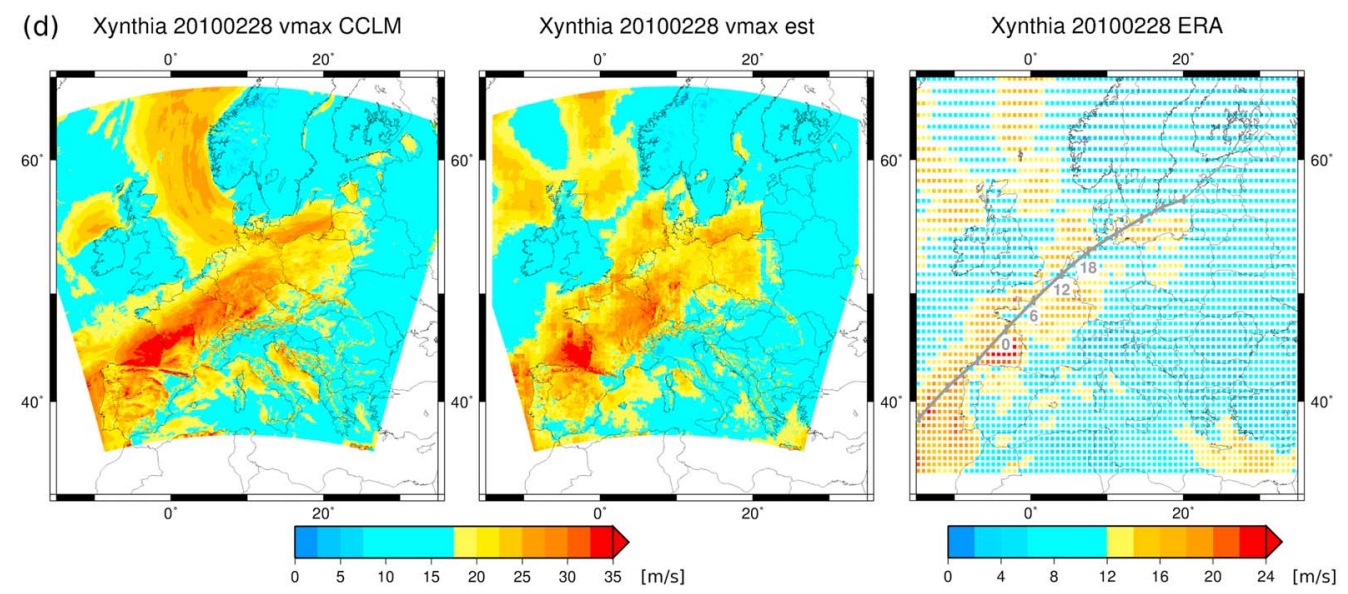

Figure 1. Three-day-signatures of the leave-one-out validation for selected events: (a) Wiebke, (b) Martin, (c) Kyrill, and (d) Xynthia. Dates are labeled as YYYYMMDD. (left) Original CCLM simulated gusts vmax. (middle) Estimated statistically downscaled gusts vmax est. (right) ERA-Interim wind speeds and 6-hourly positions of the associated cyclone tracks, marked as thick lines for the event days and thin lines for following days. UTC is only given for day two of the 3-day-signature. 

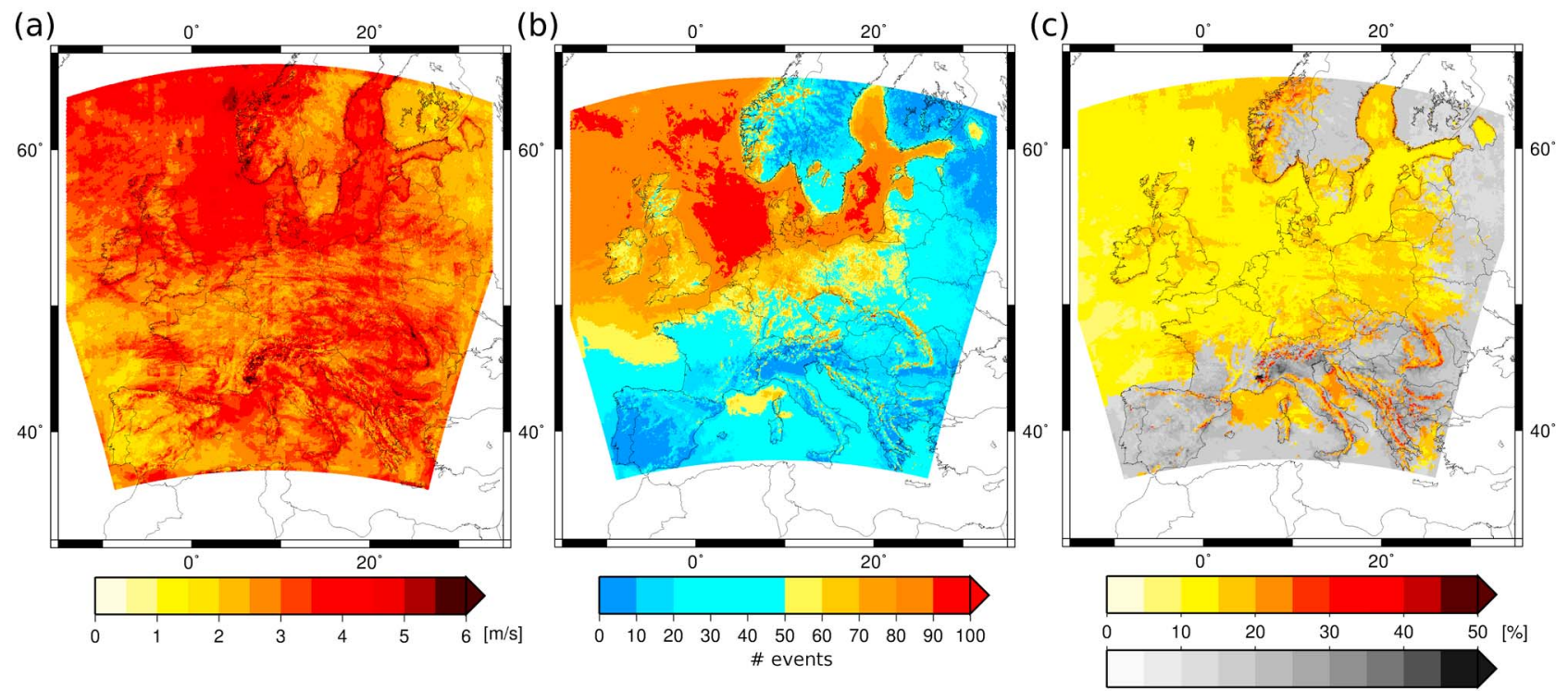

(d)
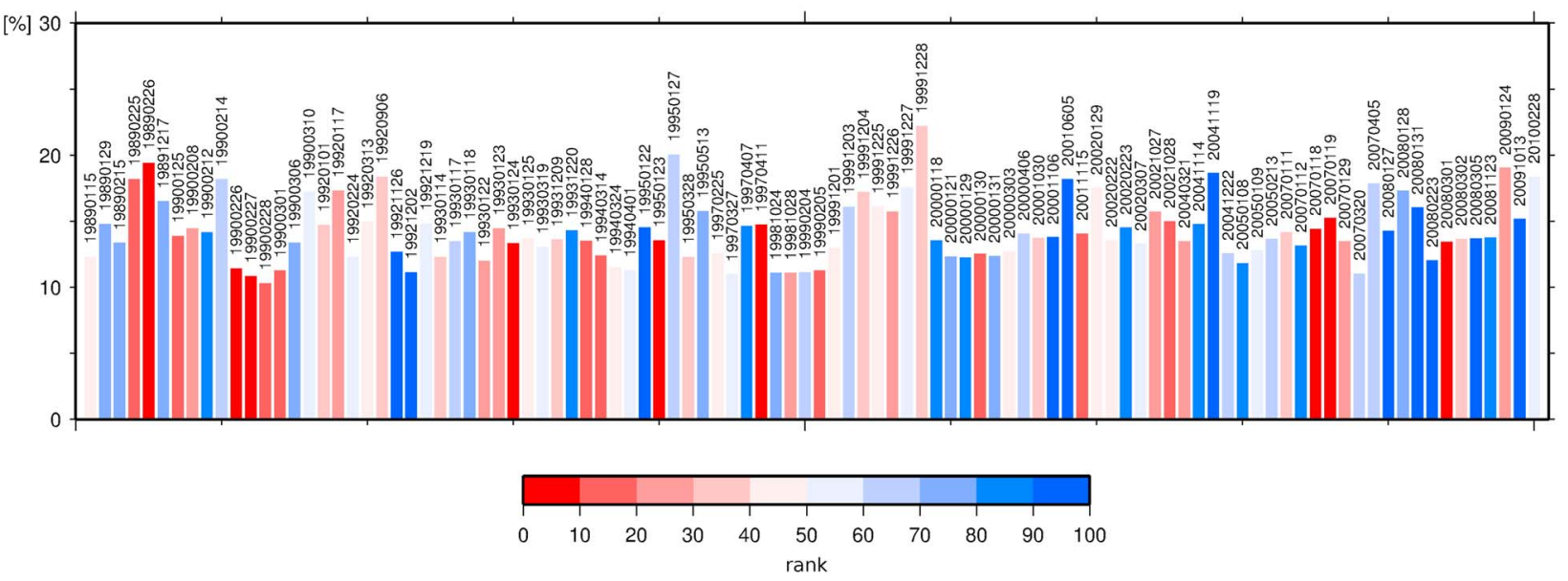

Figure 2. (a) Absolute RMSE of leave-one-out validation summed over events in $\mathrm{ms}^{-1}$. (b) Number of events per grid point with gust speeds greater equal $20 \mathrm{~ms}^{-1}$. (c) Relative RMSE of leave-one-out validation summed over all events in $\%$. Colored grid points have a model height below $2000 \mathrm{~m}$ and are hit by gust speeds greater or equal $20 \mathrm{~ms}^{-1}$ on at least 33 of the 100 events. All other grid points are shaded in gray. (d) Relative RMSE of leave-one-out validation summed over the colored grid points in \%. Bars are colored according to the rank of MI of each event (red is top rank; blue is low rank). Dates are given above each (YYYYMMDD).

[13] The 100 events have relative errors of 10-20\% averaged over the colored area (Figure 2d). These deviations are randomly distributed, which means they are not correlated to MI or rank according to MI (compare colors of bars). A detailed analysis of the wind signatures (Figure 1) indicates that the location of the footprint plays indeed an important role for the skill of the technique. In fact, $R M S E_{r e l}$ averaged over all events and grid points decreases from $16 \%$ to $14 \%$ by the selection of colored areas in Figure 2c.

[14] A second validation approach is to split the dataset into training and validation period. The periods are separated sequentially by dates (first and second 50 days) or by MI rank (more severe events and less severe events). Additionally, the original dataset is split disordered according to even and odd entry numbers of the dates or of the MI ranks, thus each second value will be used for validation. The results are similar as for the leave-one-out validation: The selection of colored areas (Figure 2c) brings a slight improvement of about $2 \%$ for both sequential and disordered periods (Table 1). Regarding sequential periods, the difference between choosing higher or lower MIs as training period is marginal. The separation by dates shows slightly better results for the estimation of the earlier period than for the later period. This could be associated with an enhanced number of difficult cases (e.g., uncommon footprints or multiple footprints per event) during this later period.

[15] Finally, the quality of the results of the statistical downscaling is compared exemplary to those of pure dynamical downscaling against observations in Germany, as here the dataset of measurements is sufficiently large and quality-proofed unlike other countries. 39 test sites are selected according to the best data availability (Table S2). For each test site, the maximum wind gust observation (1-day- or 3-daymaxima) is compared to downscaled gusts at the nearest CCLM grid point. The scattering of the values of both downscaling methods around the optimal diagonal is similar 
Table 1. $R M S E_{r e l}$ in \% for Cross-Validation With Training and Validation Periods ${ }^{\mathrm{a}}$

\begin{tabular}{cccccc}
\hline Validation Period & Training Period & $\begin{array}{c}\text { Sequential } \\
\text { All Grid Points }\end{array}$ & $\begin{array}{c}\text { Disordered } \\
\text { All Grid Points }\end{array}$ & $\begin{array}{c}\text { Sequential Selected } \\
\text { Grid Points }\end{array}$ & $\begin{array}{c}\text { Disordered Selected } \\
\text { Grid Points }\end{array}$ \\
\hline dates 1 & dates 2 & 16.56 & 15.66 & 14.42 & 13.84 \\
dates 2 & dates 1 & 17.39 & 16.12 & 15.67 & 14.18 \\
MIs 1 & MIs 2 & 16.37 & 15.95 & 14.58 & 14.08 \\
MIs 2 & MIs 1 & 16.90 & 16.00 & 14.77 & 14.08 \\
\hline
\end{tabular}

${ }^{a}$ Dates 1 are for the sequential case the first 50 days and dates 2 the 50 later ones. MIs 1 are for the sequential case the more severe events and MIs 2 the less severe ones. Selected grid points have (i) a model height under $2000 \mathrm{~m}$ and (ii) gust speeds reaching $20 \mathrm{~ms}^{-1}$ on at least on 33 of the 100 events.

(see Figure 3a for 3-day-maxima). In fact, the RMSE is slightly better for the statistical than for the dynamical downscaling (4.30 ms $\mathrm{ms}^{-1}$ vs. $\left.4.51 \mathrm{~ms}^{-1}\right)$. This tendency is also found for the mean deviations summed over all events (Figure 3b). Thus, the results of the statistical approach are at least as good as the original CCLM values. This demonstrates the ability of the statistical downscaling to reproduce reliable gust speeds on a high-resolution grid. As Germany features a wide range of landscapes from lowland coastal areas to high alpine regions, the results are assumed to be representative for other European countries.

\section{Summary and Conclusions}

[16] We have introduced and validated a new statistical downscaling tool to derive wind or gust speeds on a smallscale grid over Europe using CCLM simulations as training data. ERA-Interim data and CCLM output of 100 selected windstorm events are related by a MLR model. The crossvalidation shows that the statistical MLR model is able to reproduce dynamically downscaled wind signatures well, with relative errors of $10-20 \%$ per event, and is thus a cost-efficient alternative. Larger deviations are obtained for high altitudes [cf. also Bernardin et al., 2009], for events with multiple footprints or events affecting locations rarely hit by windstorms. The windstorms associated with untypical weather situations, which are currently not well captured by the training dataset of dynamical downscaled footprints, could be improved by a larger set of events. Compared to observations, the results of this statistical approach are in Germany at least as good as the dynamical downscaling.

[17] The proposed combination of statistical and dynamical downscaling permits to apply once obtained regression coefficients to large datasets to produce a wide sample of high-resolution wind signatures. This is a clear advantage to pure dynamical downscaling that is limited by its prohibitive computational costs. On the other hand, the use of dynamical downscaled wind gusts for training the method enables to overcome the obvious handicaps of a purely statistical approach, e.g., regarding the representation of smaller scale effects like flow deviation and channeling due to orographic features. These effects are included here, provided they are represented in the RCM simulations. A better representation of such effects might be obtained by considering RCM simulations at higher spatial resolution. Compared to other statistical downscaling techniques applied on wind or (a)

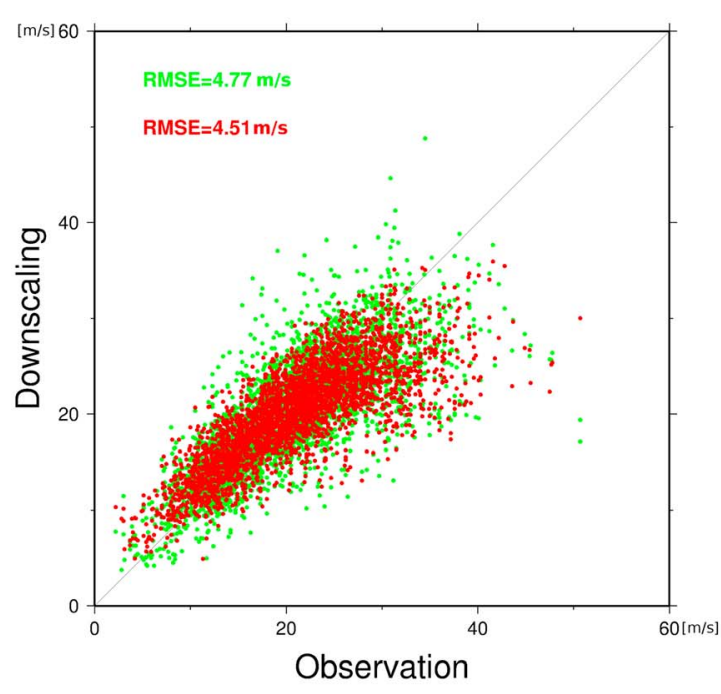

(b)

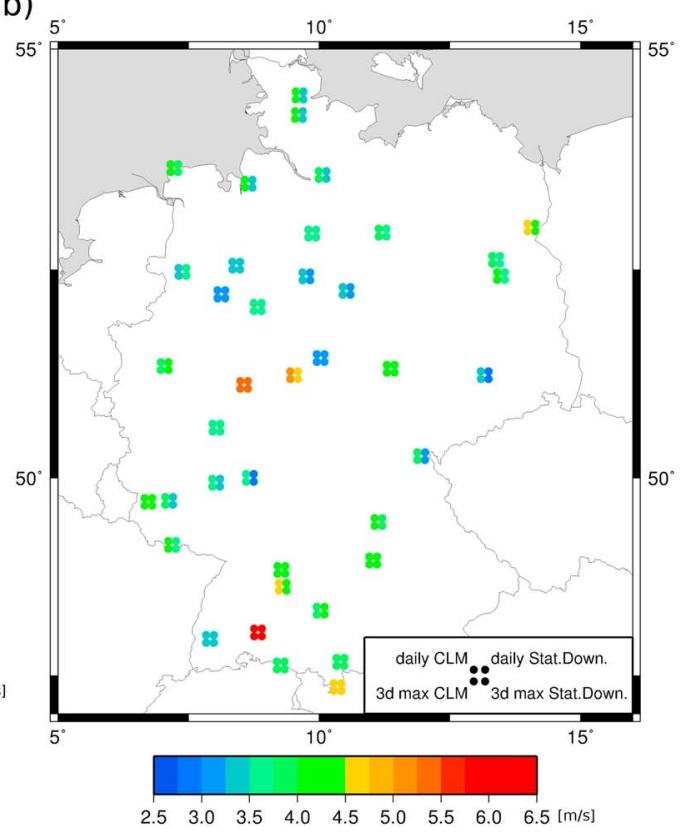

Figure 3. (a) Observations of 100 events and 39 test sites against dynamically downscaled values (green) and statistically downscaled values (red). All values are the maxima of three days. For the calculation of the RMSE $n=390, \hat{x}=$ observations, and $x=$ downscaled values. (b) RMSE of dynamical downscaling (left points) and statistical downscaling (right points) for daily values (top points) and for 3-day-maxima (bottom points). The errors are calculated as for Figure $3 \mathrm{a}$. 
gusts, this method is quite straightforward to apply on other datasets and model domains.

[18] The intention of this study was to reproduce the dynamically downscaled wind signatures. Future investigations will focus on model output statistics to calibrate the downscaled wind signatures to observations. The probability distributions of simulations and observations may be related by probability mapping [e.g., Haas and Born, 2011]. This would enable to correct the footprints and apply the approach on pre-adjusted gust speeds.

[19] Acknowledgments. We thank the ECMWF for the ERA-Interim Reanalysis dataset. This research was supported by the German Federal Ministry of Education and Research (BMBF) under the project Probabilistic Decadal Forecast for Central and Western Europe (MIKLIP-PRODEF, contract 01LP1120A). We thank K. Born and P. Ludwig for the CCLM runs, and M. K. Karremann for help with windstorm ranking. We also thank two anonymous reviewers for their constructive comments.

[20] The Editor thanks the two anonymous reviewers for their assistance in evaluating this paper.

\section{References}

Bernardin, F., M. Bossy, C. Chauvin, P. Drobinski, A. Rousseau, and T. Salameh (2009), Stochastic downscaling method: Application to wind refinement, Stochastic Environ. Res. Risk Assess., 23, 851-859.

Born, K., P. Ludwig, and J. G. Pinto (2012), Wind gust estimation for mid-European winter storms: Towards a probabilistic view, Tellus, Ser. A, 64, 17471, doi:10.3402/tellusa.v64i0.17471.

Dee, D. P., et al. (2011), The ERA-Interim reanalysis: Configuration and performance of the data assimilation system, Q. J. R. Meteorol. Soc., $137,553-597$.

Della-Marta, P. M., and J. G. Pinto (2009), Statistical uncertainty of changes in winter storms over the North Atlantic and Europe in an ensemble of transient climate simulations, Geophys. Res. Lett., 36, L14703, doi:10.1029/2009GL038557.
Della-Marta, P. M., M. A. Liniger, C. Appenzeller, D. N. Bresch, P. KöllnerHeck, and V. Muccione (2010), Improved estimates of the European winter windstorm climate and the risk of reinsurance loss using climate model data, J. Appl. Meteorol. Climatol., 49, 2092-2120.

De Rooy, W. C., and K. Kok (2004), A combined physical-statistical approach for the downscaling of model wind speed, Weather Forecast., 19, 485-495.

Fink, A. H., T. Brücher, V. Ermert, A. Krüger, and J. G. Pinto (2009), The European storm Kyrill in January 2007: Synoptic evolution, meteorological impacts and some considerations with respect to climate change, Nat. Hazards Earth Syst. Sci., 9, 405-423.

Haas, R., and K. Born (2011), Probabilistic downscaling of precipitation data in a subtropical mountain area: A two-step approach, Nonlinear Processes Geophys., 18, 223-234.

Kjellström, E., G. Nikulin, U. Hansson, G. Strandberg, and A. Ullerstig (2011), 21st century changes in the European climate: Uncertainties derived from an ensemble of regional climate model simulations, Tellus, Ser. $A, 63,24-40$.

Klawa, M., and U. Ulbrich (2003), A model for the estimation of storm losses and the identification of severe winter storms in Germany, Nat. Hazards Earth Syst. Sci., 3, 725-732.

Maraun, D., et al. (2010), Precipitation downscaling under climate change: Recent developments to bridge the gap between dynamical models and the end user, Rev. Geophys., 48, RG3003, doi:10.1029/2009RG000314.

Pinto, J. G., M. K. Karremann, K. Born, P. M. Della-Marta, and M. Klawa (2012), Loss potentials associated with European windstorms under future climate conditions, Clim. Res., 54, 1-20.

Pryor, S. C., J. T. Schoof, and R. J. Barthelmie (2005), Empirical downscaling of wind speed probability distributions, J. Geophys. Res., 110, D19109, doi:10.1029/2005JD005899.

Rockel, B., A. Will, and A. Hense (2008), The regional climate model COSMO-CLM (CCLM), Meteorol. Z., 17, 347-348.

Schulz, J. P. (2008), Revision of the turbulent gust diagnostics in the COSMO model, COSMO Newsl., 8, 17-22.

Schwierz, C., P. Köllner-Heck, E. Zenklusen Mutter, D. N. Bresch, P.-L Vidale, M. Wild, and C. Schär (2010), Modelling European winter wind storm losses in current and future climate, Clim. Change, 101, 485-514. 